زمانى بهرهبردارى مشخص معطوف كردند و به بررسى خرابى يرداخته|ند. [Tו-19]

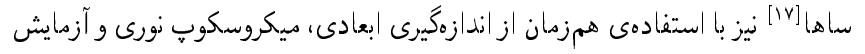

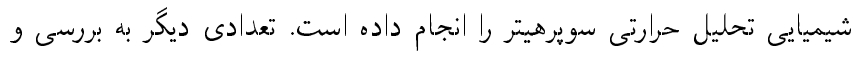

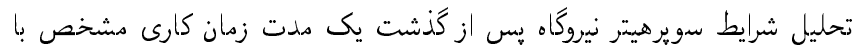

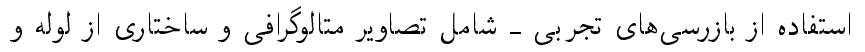

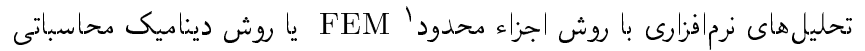

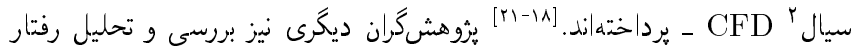

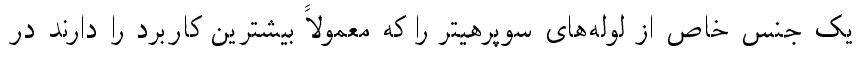

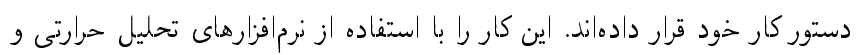

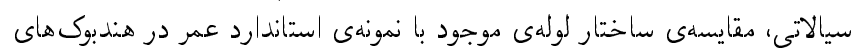

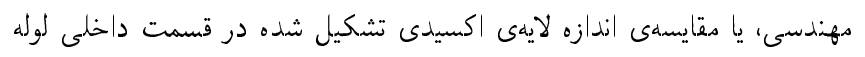
انجام دادند. [ro-ror

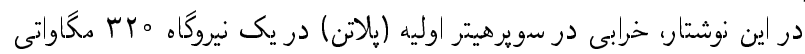

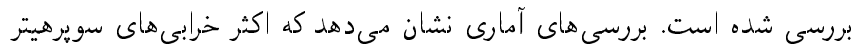

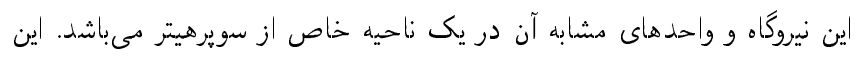

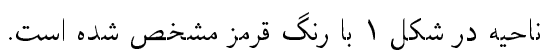

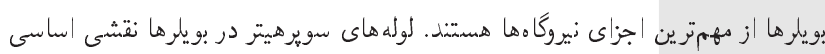

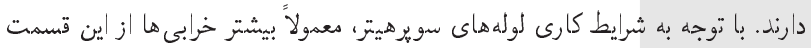

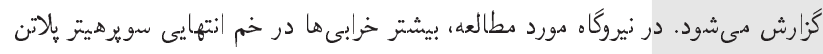

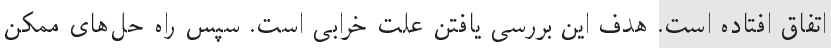

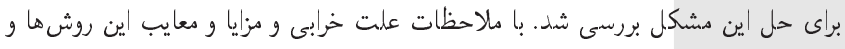

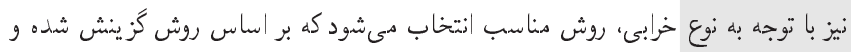

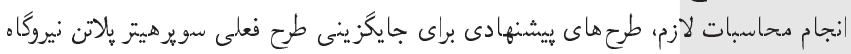

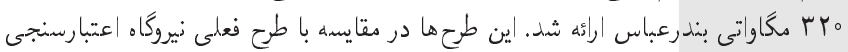

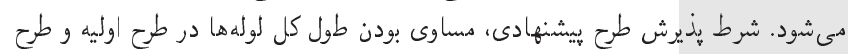

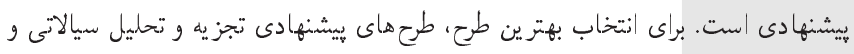

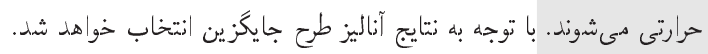

يكى از دهمتر ين و بحرانى ترين اجزاى بويلر، سويرهيترها هستند. [1] عدم نكهدارى و

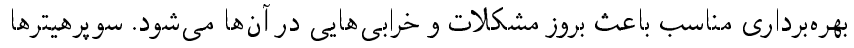

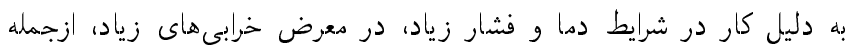

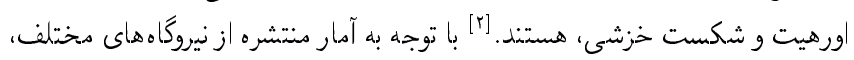

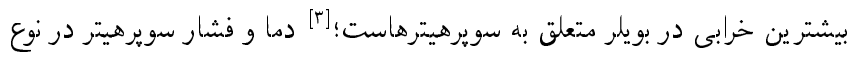

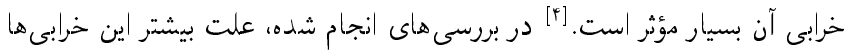

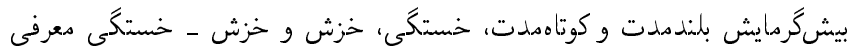

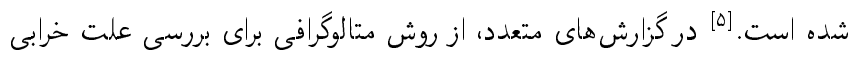

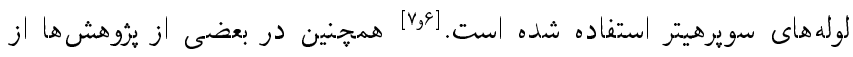

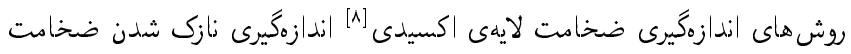

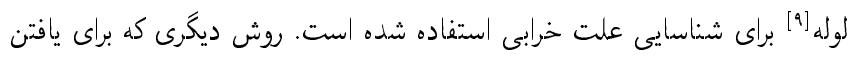

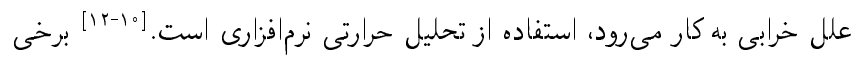

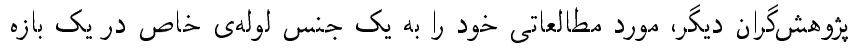

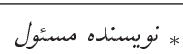
تاريخ: دريافت DOI:10.24200/J40.2020.54621.1535 


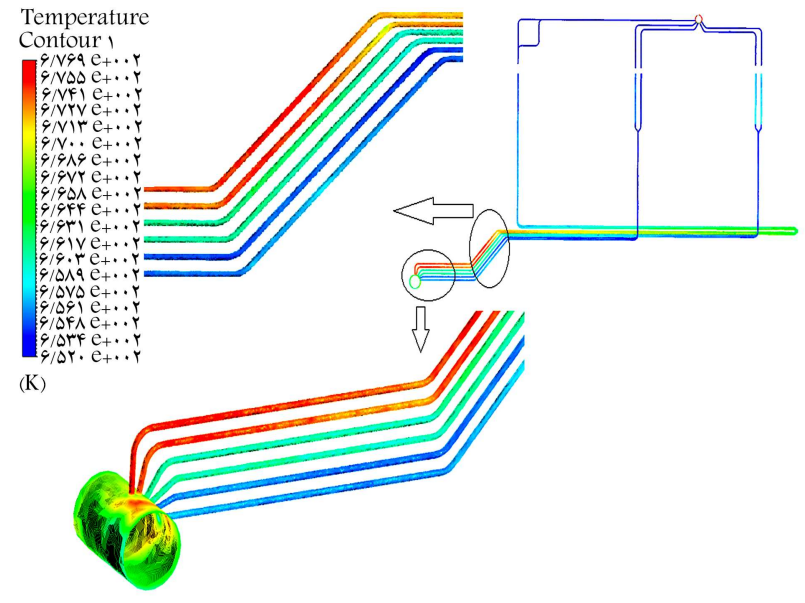

شكل r. دماى لولههاى سو يرهيتر يلاتن نيروگاه مبr مگاواتى.

F. . مىتوان لولهى بلندتر را با لولهيى با قطر بزرگتر جايكز ين كرد تا كمبود دبى جبران

شود.

ه. تعويض موضعى لولههاى آسيبديده به فاصلهى ا متر از خمها با لولهى نو،

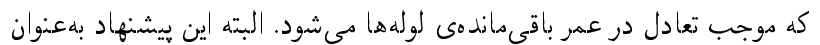

$$
\text { راه حل موقت است. }
$$

اين بيشنهادها همراه با مزايا و معايب هر كدام در جدول ا 1 قابل مشاهده است.

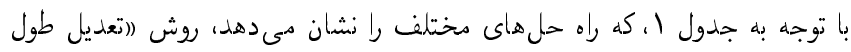

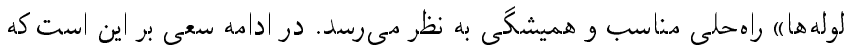
طرح هايى متناسب با همين هدف ارائه شود.

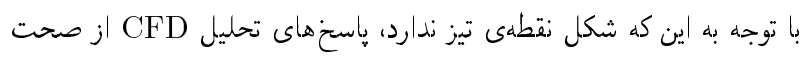

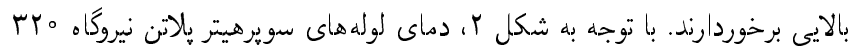

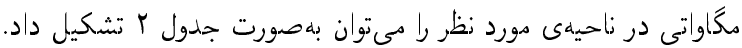

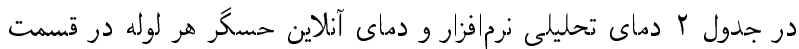

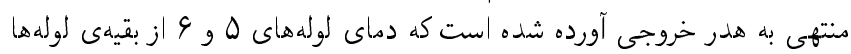

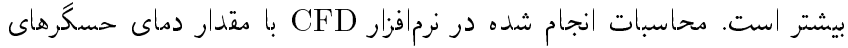

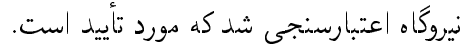

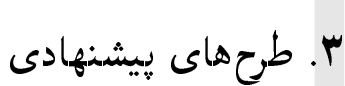

طرح هاى ارائه شده بهعنوان طرح ييشنهادى، بايد از اندازههاى هندسى و شرايط كارى

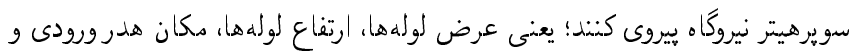

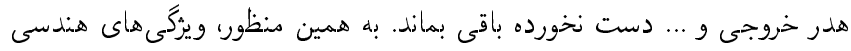

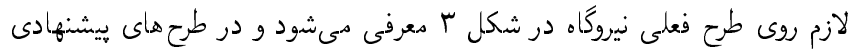

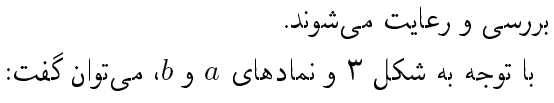

$L_{R}=r a+b$

$L_{R, C}=r a+r b$

$L_{T}=\mid{ }_{a} a+\boldsymbol{F}_{b}$

رابطهى ( براى دحاسبه طول لوله هاى تحت تشعشع مستقيم، رابطهى Y براى محاسبهى

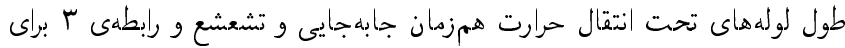

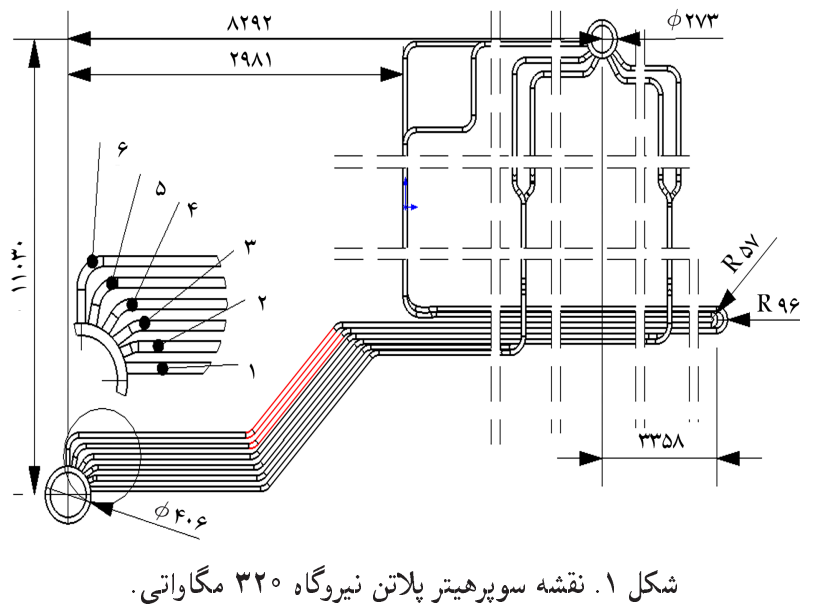

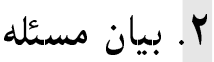

در اين نوشتار با توجه به خرابى سويرهيتر نيروكاه، سعى شده روشى براى جلوكيرى

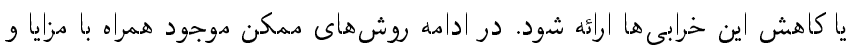

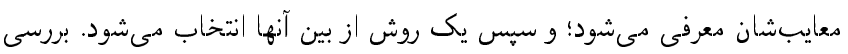

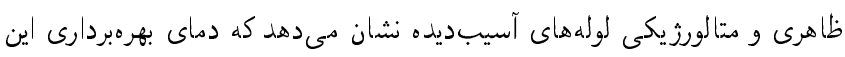

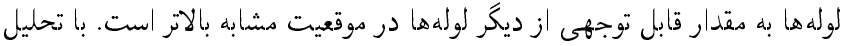

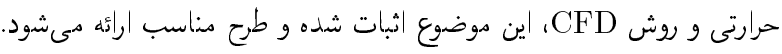

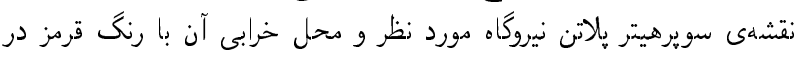

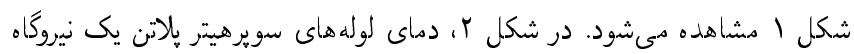

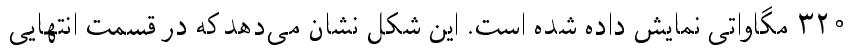

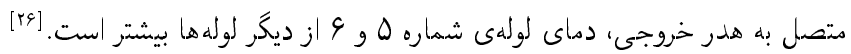

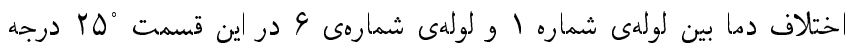

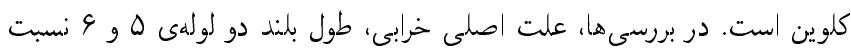

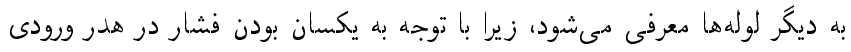

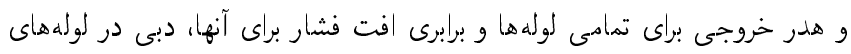

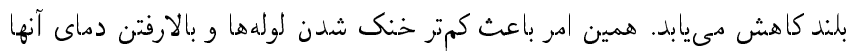

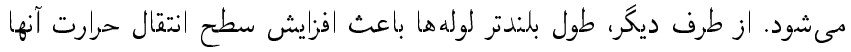

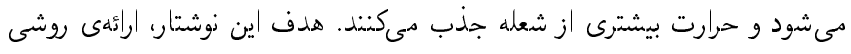

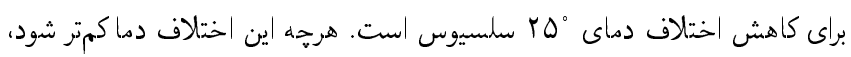
احتمال خرابى نيز كمتر مى شود و طول عمر نيروكاه افزايش مى ميابد.

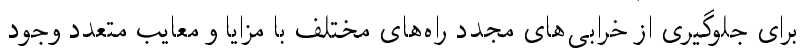

I. مىتوان جنس لولهى بلندتر را با جنس مقاومترى كه داراى عناصر آليازى بيشترى

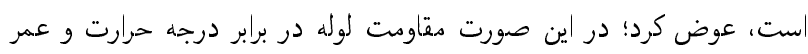
خزشى آن افزايش خواهد يافت.

r. با تغيير در طول لولهها و نوع آرايش آنها مىتوان دبى عبورى از لولهها را متعادل

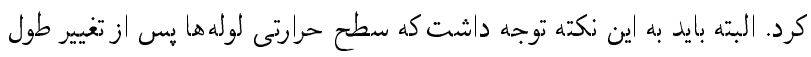

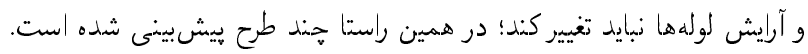
r. قرار دادن اريفيس مناسب در ابتداى لولههاى كوتاه باعث كم شدن جريان در

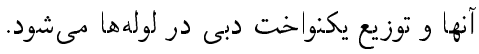


جدول 1. راهحلها با مزايا و معايب آنها.

\begin{tabular}{|c|c|c|}
\hline معايب & 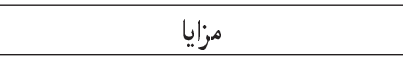 & 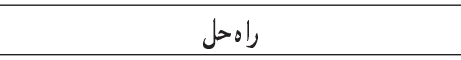 \\
\hline اختلاف دما ثابت مى ماند، هزينه زياد مىشود. & تحمل دماى بيشتر & تعويض لوله با جنس بهتر \\
\hline هزينهى تغيير طرح و مطالعات & دماى بيشينه به دليل تعديل & تعديل طول لولهها \\
\hline نياز به انجام دحاسبات بسيار دقيق براى قطر اوريفيس دارد؛ & درنتيجه دما كاهش مى دياخت شده و & استفاده از اريفيس در ابتداى لولهها \\
\hline نياز به دحاسبات دقيق از نظر سيالاتى و حرارتى دارد. & دبى يكنواخت شده و دما كاهش مىيابد & افزايش قطر لولهى بلندتر \\
\hline موقتى است & هزينهى اجرايى كمى دارد & تعويض دوضعى لوله به فاصلهى المتر از خمها \\
\hline
\end{tabular}

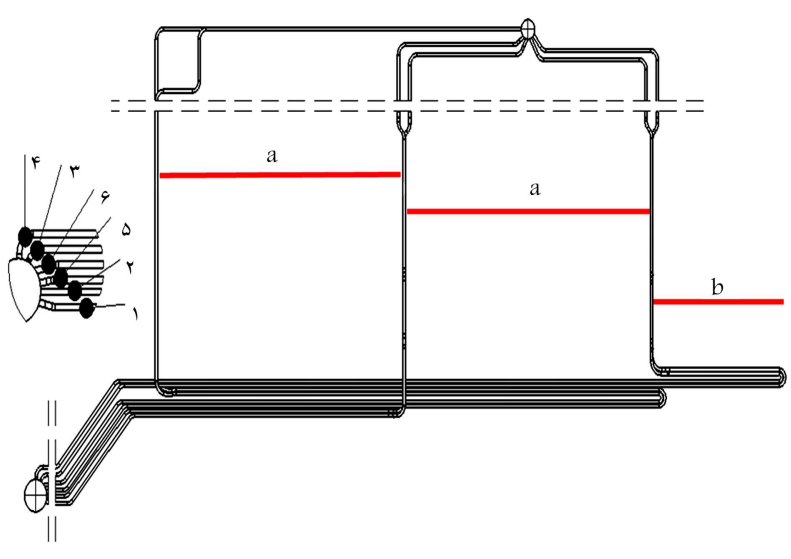

شكل F. طرح بيشنهادى شماره 1.

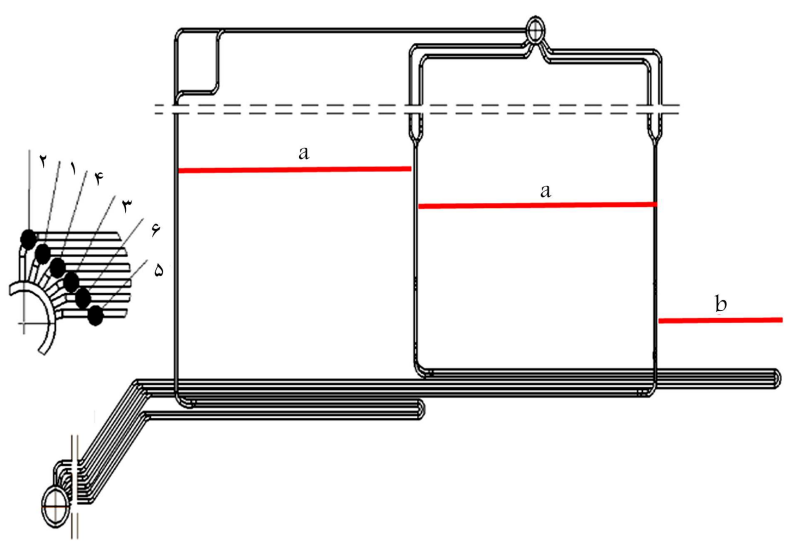

شكل ه. طرح بيشنهادى شماره r.

همانطور كه مشاهده مى شود در طرح بيشنهادى شماره ب (شكل 9)، سه خم

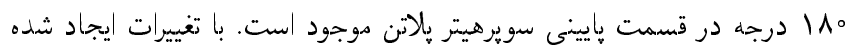

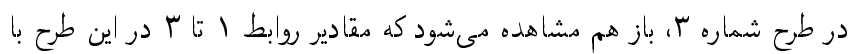

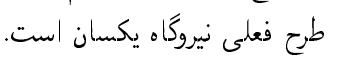

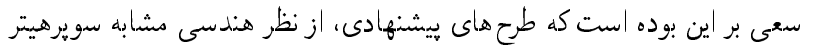

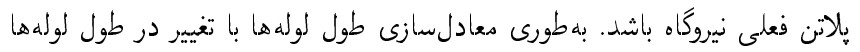

جدول r. دماى لولههاى سويرهيتر در ناحيه بحرانى.

\begin{tabular}{|c|c|c|}
\hline دماى تحليلى [K] & دماى حسكر [K] & شماره لوله \\
\hline 909 & $q \Delta r, r$ & 1 \\
\hline 9or & 901,1 & r \\
\hline 901 & $\varphi \Delta Q, V$ & r \\
\hline 909 & $901, r$ & r \\
\hline qVe & $q \vee r, 0$ & 0 \\
\hline sVV & $q V Y, q$ & 4 \\
\hline
\end{tabular}

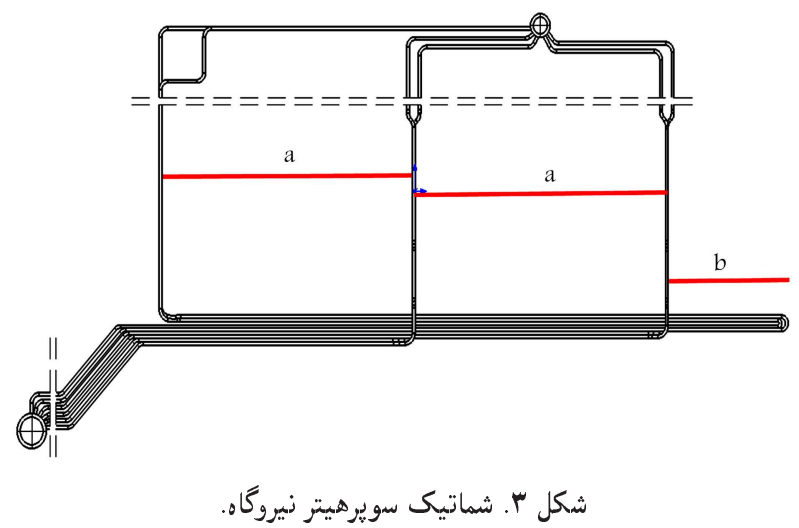

دحاسبهى طول كل لوله هاى قسمت إييين سويرهيتر كاربرد دارند. با رعايت روابط

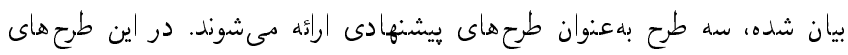

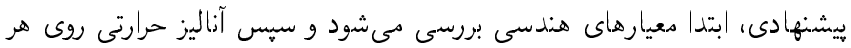

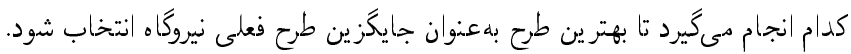

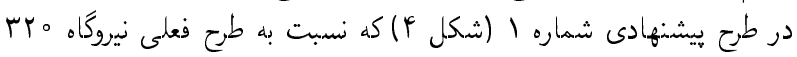

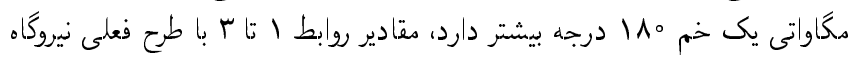
برابر است.

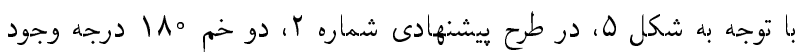

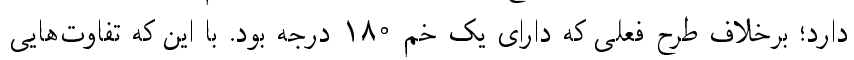

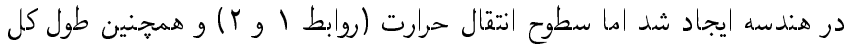
لولهها تغييرى نكرده است. 


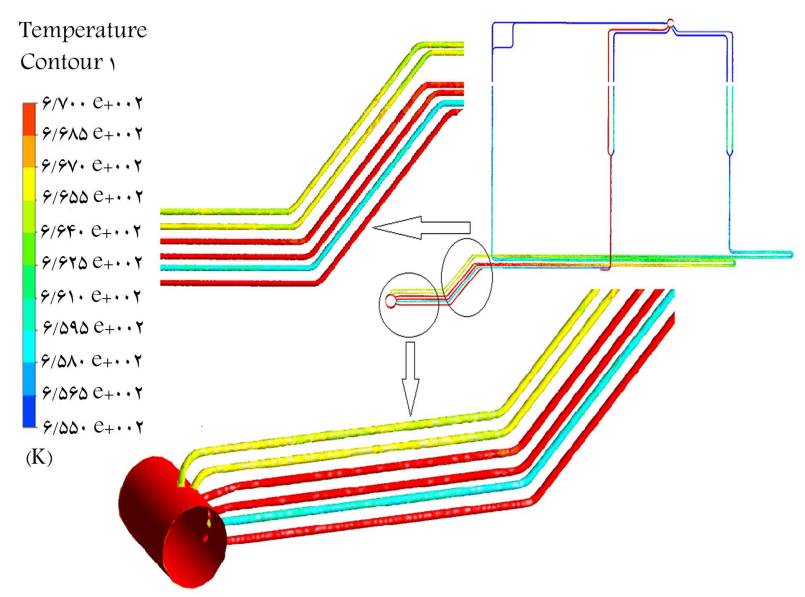

شكل V. دماى لولههاى طرح ييشنهادى شماره 1.

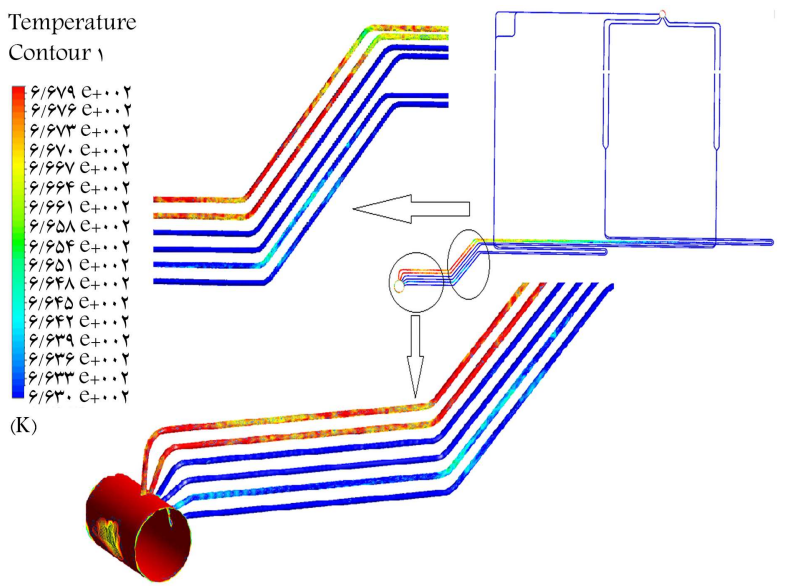

شكل ^. دماى لولههاى طرح يِيشنهادى شماره r.

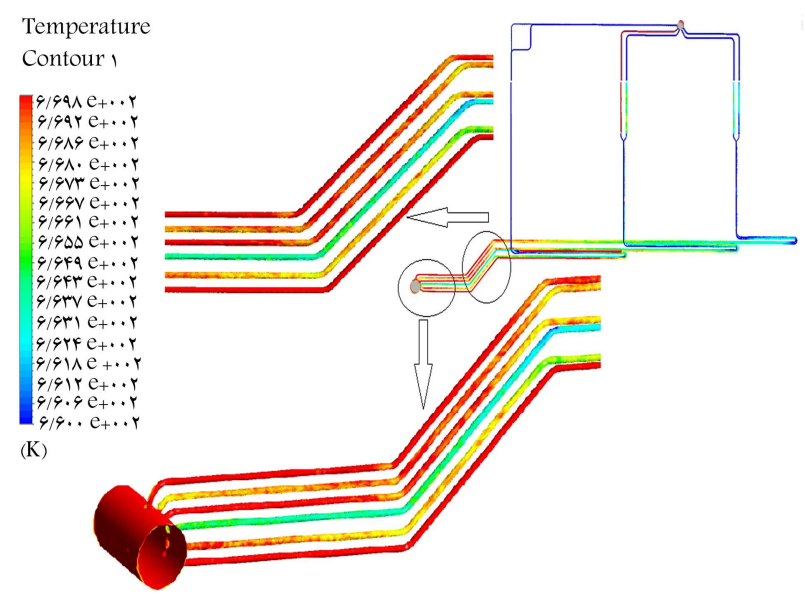

شكل 9.

در نكاه اول، بازه دمايى $9 \Delta \Delta$ تا ه \& درجه كلوين به هشم مى خورد كه نسبت

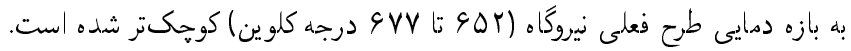

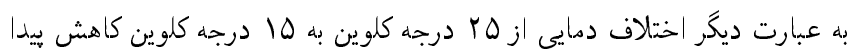
كرده است.

موضوع جالب توجه ديكر اين است كه جهار لوله از شش لولهى منتهى به هدر

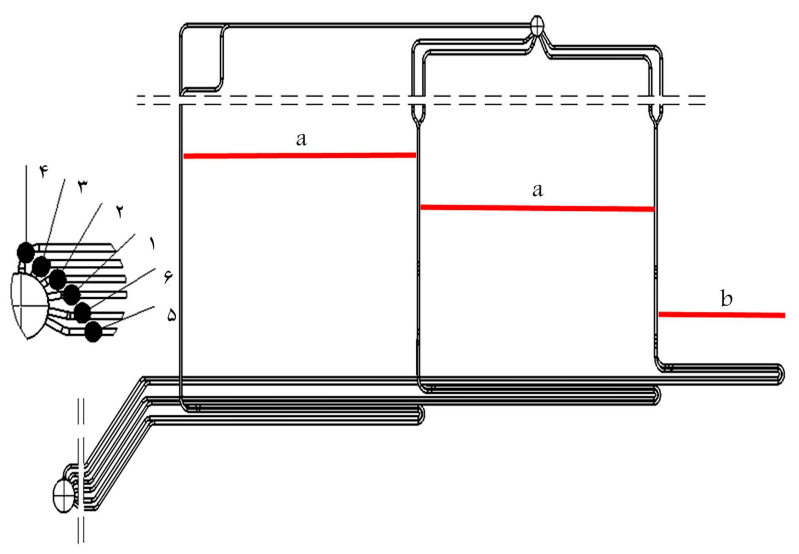

شكل 9. طرح ييشنهادى شماره ب.

\begin{tabular}{|c|c|c|c|}
\hline لولهى هوو & لولهى باوF & لولهى اوب & شماره لوله \\
\hline rapoo & rq1.0。 & YVYOo & طرح موجود \\
\hline rq०o० & rroo。 & rVYoo & طرج ييشنهادى 1 \\
\hline$r \wedge 900$ & $r 9100$ & rvo.o & طرج ييشنهادى r \\
\hline raroo & rroo。 & Mrooo & طرح ييشنهادى r \\
\hline
\end{tabular}

و تعداد خمها انجام شده است؛ در حالى كه مكان هدرهاى ورودى و خروجى و

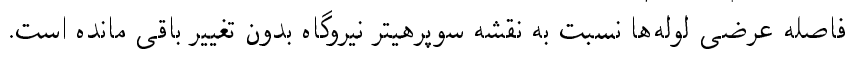

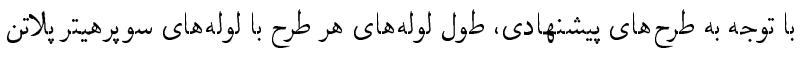

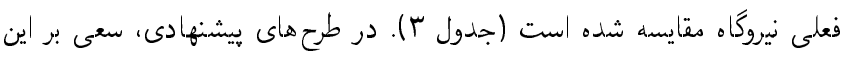

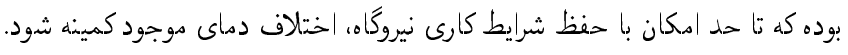

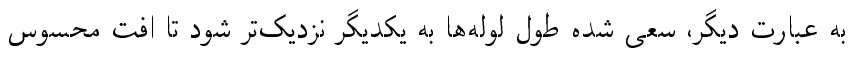

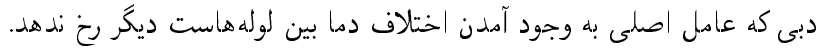

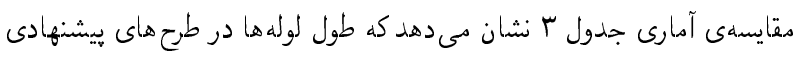

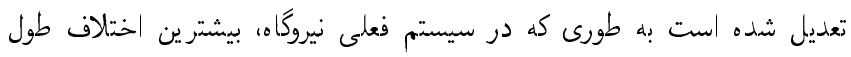

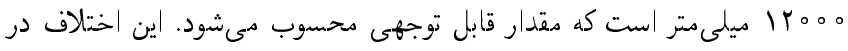

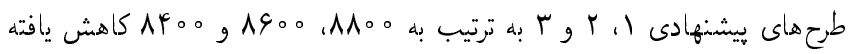

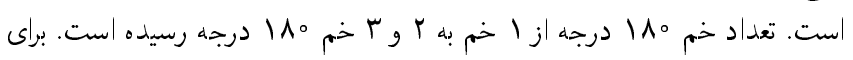

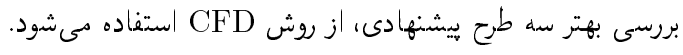

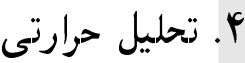

طرح هاى ييشنهادى ابتدا بهصورت سهبعدى مدل شدهاند. يس از هش زنى به به روش

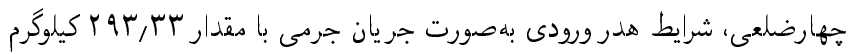

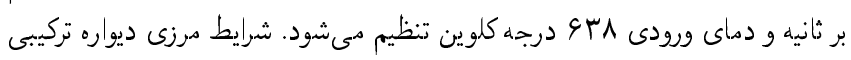

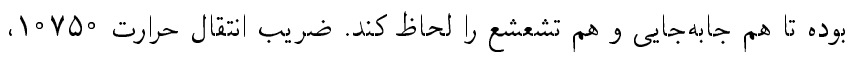

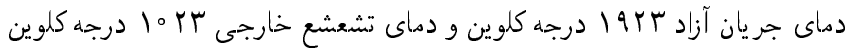

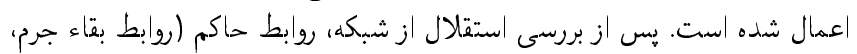

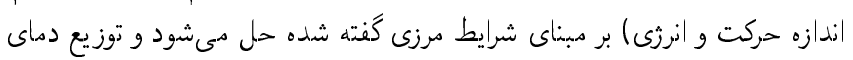

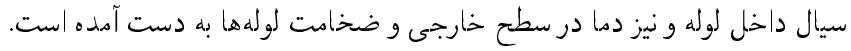

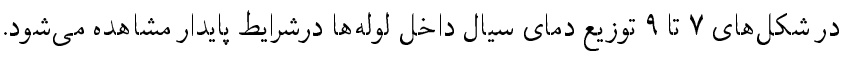


جدول f. مقايسهى دمايى نيروگاه فعلى و طرحهاى بيشنهادى.

\begin{tabular}{|c|c|c|c|}
\hline دماى ميانگگ [K] & بازه دمايى [K] & اختلاف دما [K] & 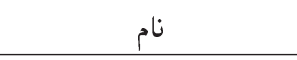 \\
\hline 990,0 & $9 V V-\varphi \Delta r$ & ro & طرح فعلى سويرهيترهاى يلاتن \\
\hline$\Leftrightarrow \notin Y, 0$ & $9 V 0-9 \Delta \Delta$ & 10 & طرح ييشنهادى شماره 1 \\
\hline 990,0 & 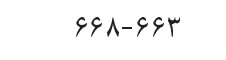 & $\Delta$ & طرح ييشنهادى شماره r \\
\hline 990 & $9 V_{0}-99_{0}$ & 10 & طرح ييشنهادى شماره r \\
\hline \multicolumn{4}{|c|}{ جدول ه. مقايسهى طرح بيشنهادى ب و بّ. } \\
\hline $\begin{array}{c}\text { اختلاف طول } \\
\text { [mm] }\end{array}$ & $\begin{array}{c}\text { دماى ميانگير } \\
\text { [K] }\end{array}$ & $\begin{array}{c}\text { بازه دمايى } \\
\text { [K] }\end{array}$ & 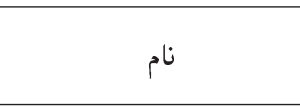 \\
\hline 1900 & 990,0 & $991-994$ & طرح ييشنهادى شماره دو \\
\hline$\varphi \Lambda_{0} \circ$ & 990 & $9 V_{0}-99_{0}^{\circ}$ & طرح ييشنهادى شماره سه \\
\hline
\end{tabular}

اين طرحهاى بيشنهادى سعى شده دماى كمينه افزايش و دماى بيشينه كاهش يابد؛

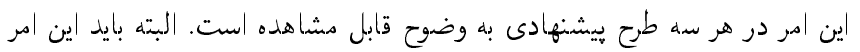

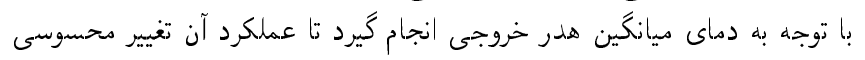

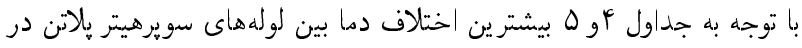

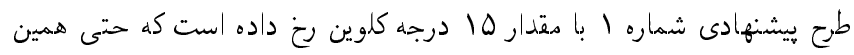

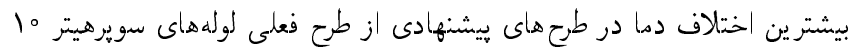

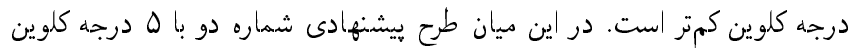

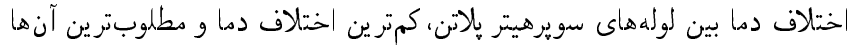

را الرائه مى دهد.

در بين طرحهاى بيشنهادى ارائه شده، طرح بيشنهادى شماره r دقيقاً دماى

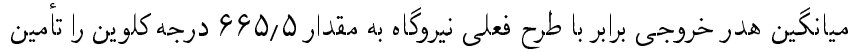

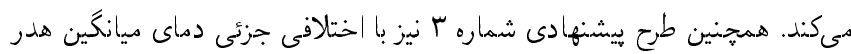

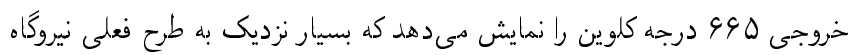

بيشتر ين دماى به دست آمده در طرحهاى بيشنهادى در بدتر ين حالت مقدار 9V。

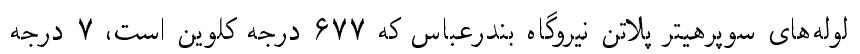
كلوين اختلاف دارد.

\section{4. بيشنهاد}

براى انتخاب بهتر ين طرح از بين سه طرح ارائه شده بر اساس موارد مورد بحث،

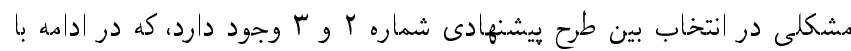
دقت بيشترى از جهات دختلف اين دو طرح دقايسه دى شئند

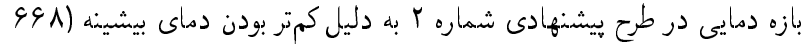

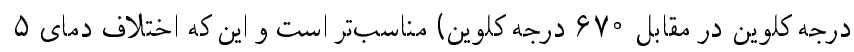

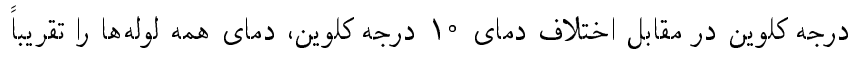

$$
\text { در يك سطح دمايى فراهم كرده است. }
$$

دماى ميانكين هدر خروجى در طرح بيشنه درده استى شماره r دقيقاً برابر با مقدار
خروجى در بازه دمايى 941 تا هV دورجه كلوين قرار دارند كه براى سيستم هندان مطلموب نيست.

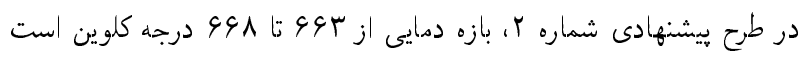

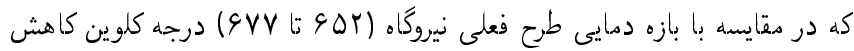

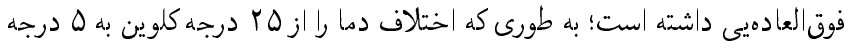

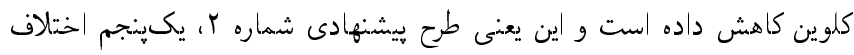
دماى طرح فعلى نيروكاه را ارائه مى دهد.

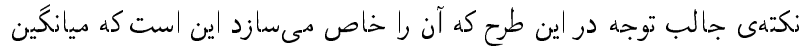

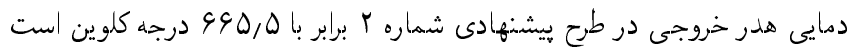

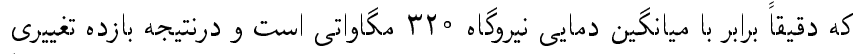
نخواهد كرد. اين موضوع در كنار كاهش اختلاف دما به يك بنّجم دقدار اوليه واقعاً بى نظير است.

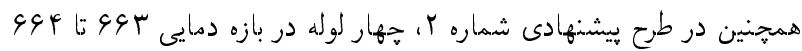

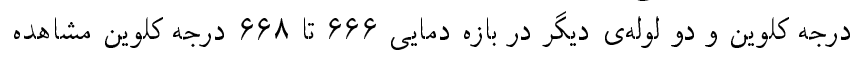

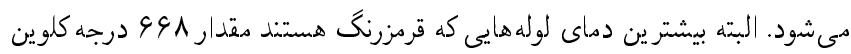

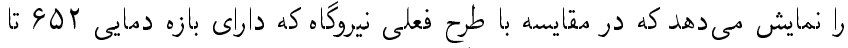
\&VV

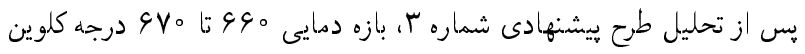

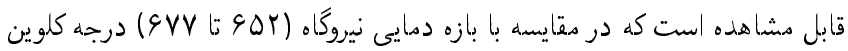

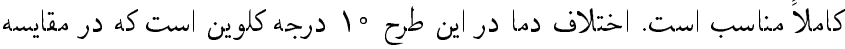

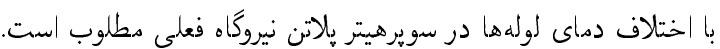

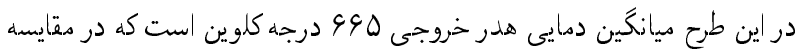

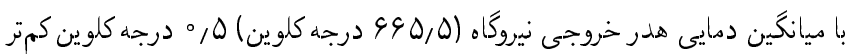

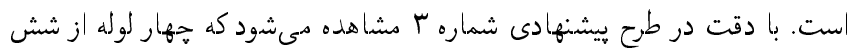

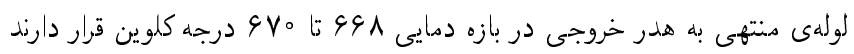

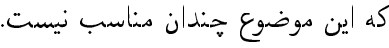

\section{ه. مقايسهى نتايج طرحها} بازه دمايى طرحهاى بيشنهادى نسبت به طرح فعلى نيروكاه كاهش يافته است. در 


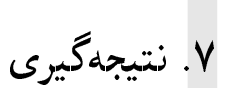

در اين يثوهش به بررسى و ارائه سه بيشنهاد براى كاهش مشكل خرابى لوله دهاى

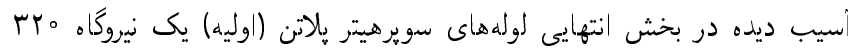

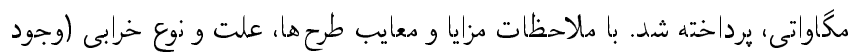

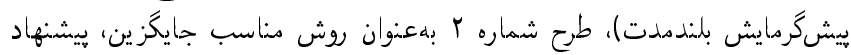

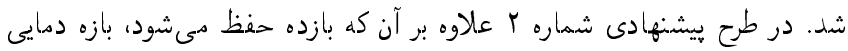

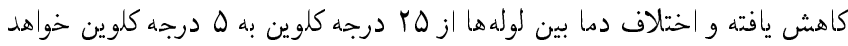

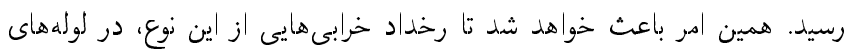
سويرهيتر هاتاتن نيروگاه كاهش يابد.

\section{تقدير و تشكر}

در اين يزوهش از خدمات (سامانه رايانش موازى دانشكاه شهيد بهشتى" (سرمد)

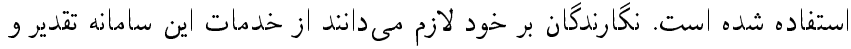
تشكر كنند.

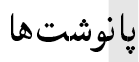

1. Finite Element Method

2. Computational Fluid Dynamic

\section{منابع (References)}

1. David, F., Metallurgical failures in fossil fired boilers, New York: A Wiley Interscience Publication (2000).

2. layer, J. and Adler, T. "Failure analysis and prevention", ASM International, 11, pp.19-40(2002).

3. Jones, D.R.H. "Creep failures of overheated boiler, superheater", Engineering Failure Analysis, 11, pp. 873893 (2004)

4. Neves, D.L.C. and Seixas, J.R.C. "Stress and integrity analysis of steam superheater", Material Research, 7(1), pp. 155-161 (2004).

5. Viswanathan, R. "An overview of failure mechanisms in high temperature components in power plants", Electric Power Research Institute, 122, pp. 246-255 (2000).

6. Psyllaki, P.P., Pantazopoulos, G. and Lefakis, H. "Metallurgical evaluation of creep-failed superheater tubes", Engineering Failure Analysis, 16, pp. 1420-1431 (2009).

7. Begum, S., Karim, A.N.M,. Zamani, A.S.M. and et al. "Wall thinning and creep damage analysis in boiler", Journal of Mechatronics, 1, pp. 1-6 (2013).

8. Pramanick, A.K., Das, G., Das, S.K. and et al. "Failure investigation of super heater tubes of coal fired power
هدر خروجى سويرهيتر هلاتن در طرح فعلى است، كه در طرح ييشنهادى شماره ب

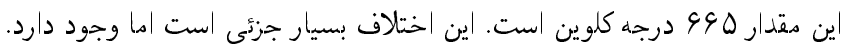

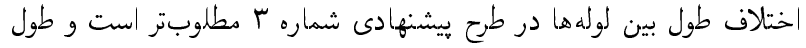

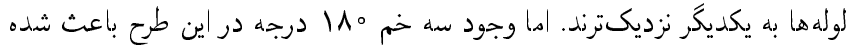

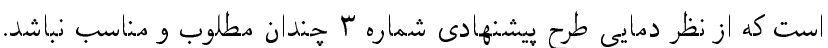

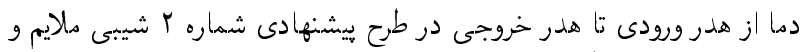

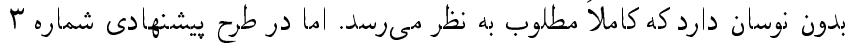

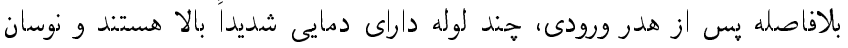

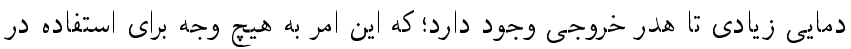

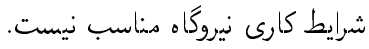

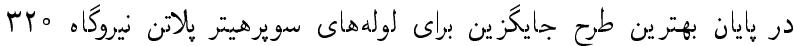

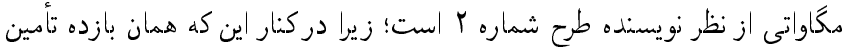

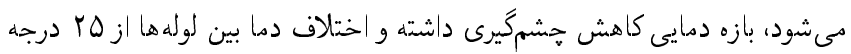

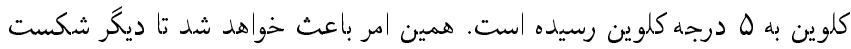

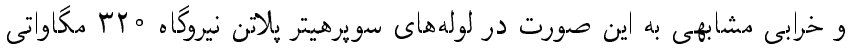
رن ندهد.

plant", Case Studies in Engineering Failure Analysis, 9, pp. 17-26 (2017).

9. Movahedi-Rad, A., Plasseyed, S.S. and Attarian, M. "Failure analysis of superheater tube", Engineering Failure Analysis, 48, pp. 94-104 (2015).

10. Othman, H., Purbolaksono, J. and Ahmad, B. "Failure investigation on deformed superheater tubes", Engineering Failure Analysis, 16, pp. 329-339 (2009).

11. Purbolaksono, J., Ahmad, J., Khinani, A. and et al. "Failure case studies of SA213-T22 steel tubes of boiler through", Journal of Loss Prevention in the Process Industries, 23, pp. 98-105 (2010).

12. Al-Kayiem, H.H. and Albarody, T.M.B. "Numerical investigation of superheater", WTT Transactions on Engineering Sciences, 106, pp. 1743-3533 (2016).

13. Liang, Z., Jin, X. and Zhao, Q. "Investigation of overheating of the final super-heater", Engineering Failure Analysis, 45, pp. 59-64 (2014).

14. Purbolaksono, J., Ahmad, J., Beng, L.C. and et al. "Failure analysis on a primary superheater tube of a power plant", Engineering Failure Analysis, 17, pp. 158-167 (2010).

15. Dehnavi, F., Eslami, A. and Ashrafizadeh, F. "A case study on failure of superheater tubes in an industrial power", Engineering Failure Analysis, 80, pp. 368-377 (2017).

16. Fetni, S., Toumi, A., Mkaouar, I. and et al. "Microstructure evolution and corrosion behaviour of an ASTM A213 T91 tube after long term creep exposure", Engineering Failure Analysis, 79, pp. 575-591 (2017). 
17. Saha, A. and Roy, H. "Failure investigation of a secondary super heater tube in a $140 \mathrm{MW}$ thermal power plant", Case Studies in Engineering Failure Analysis, 7, pp. 57-60 (2017).

18. Liang, Z., Jin, X. and Zhao, Q. "Investigation of overheating of the final super-heater", Engineering Failure Analysis, 45, pp. 59-64 (2014).

19. Moussavi Torshizi, S.E. and Jahangiri, A. "Analysis of fatigue-creep crack growth in the superheater header of a power plant boilers and estimation of its remaining lifetime", Journal of Failure Analysis and Prevention, 18, pp. 189-198 (2018).

20. Dehnavi, F., Eslami, A. and Ashrafizadeh, F. "A case study on failure of superheater tubes in an industrial power", Engineering Failure Analysis, 80, pp. 368-377 (2017).

21. Fetni, S. Toumi, A., Mkaouar, I. and et al. "Microstructure evolution and corrosion behaviour of an ASTM A213 T91 tube after long term creep exposure", Engineering Failure Analysis, 79, pp. 575-591 (2017).
22. Tibba, G.S. and Altenbach, H. "Modelling creep behaviour of superheater materials", Energy Procedia, 93, pp. 197-202 (2016).

23. Goyal, S., Mariappan, K., Shankar, V. and et al. "Studies on creep-fatigue interaction behaviour of Alloy 617M", Materials Science and Engineering: A, 730, pp. 16-23 (2018).

24. Qi, J. Zhou, K. Huang, J. and et al. "Numerical simulation of the heat transfer of superheater tubes in power plants considering oxide scale", International Journal of Heat and Mass Transfer, 122, pp. 929-938 (2018).

25. Kauppila, P., Kouhia, R., Ojanpera, J. and et al. "Sorjonen, a continuum damage model for creep fracture and fatigue analyses", Procedia Structural Integrity, 2, pp. 887-894 (2016).

26. Shami, A.A., Moussavi Torshizi, S.E. and Jahangiri, A. "Experimental and computational investigation of platen superheater failure in 320 MW power plant", Modares Mechanical Engineering, 20(2), pp. 509-514 (2020). 